\title{
Clinical data from the real world: efficacy of Crizotinib in Chinese patients with advanced ALK-rearranged non-small cell lung cancer and brain metastases
}

\author{
Puyuan Xing ${ }^{1, *}$, Shouzheng Wang ${ }^{1, *}$, Xuezhi Hao ${ }^{1}$, Tongtong Zhang ${ }^{1}$, Junling Li $^{1}$ \\ ${ }^{1}$ Department of Medical Oncology, Cancer Hospital, Chinese Academy of Medical Sciences (CAMS) and Peking Union Medical \\ College (PUMC), Beijing, China \\ *These authors contributed equally to this work and should be considered co-first authors
}

Correspondence to: Junling Li, email: lijunling@cicams.ac.cn

Keywords: NSCLC, crizotinib, brain metastasis, chinese, real world

Received: June 29, $2016 \quad$ Accepted: October 28, $2016 \quad$ Published: November 07, 2016

\section{ABSTRACT}

Brain metastasis in non small cell lung cancer (NSCLC) patients is often considered as a terminal stage of advanced disease. Crizotinib is a small-molecule tyrosine kinase inhibitor (TKI) for ALK-rearranged NSCLC patients. Herein, we conducted a retrospective study to explore how Crizotinib affects the control of brain metastases and the overall prognosis in advanced ALK-rearranged NSCLC patients with brain metastases in Chinese population. A total of $\mathbf{3 4}$ patients were enrolled, of whom $20(58.8 \%)$ patients had baseline brain metastases before Crizotinib treatment. Among patients with brain metastases before Crizotinib, overall survival (OS) after brain metastases was significantly longer than that of patients with brain metastases after Crizotinib (median OS, not reached vs. 10.3 months, respectively, $p=0.001$ ). There was also a significant difference in systemic progression-free survival (PFS) between patients developing brain metastases before and after Crizotinib treatment (21.2 months vs. 13.9 months, $p=0.003$ ). In conclusion, ALK-rearranged NSCLC patients with brain metastases before Crizotinib may benefit more from Crizotinib than those developing brain metastases during Crizotinib treatment.

\section{INTRODUCTION}

Lung cancer has been the leading cause of cancerrelated deaths both worldwide [1] and in China [2], among which $85 \%$ are non small cell lung cancer (NSCLC), mainly including adenocarcinoma and squamous cell carcinoma [3]. A large number of NSCLC patients have been at advanced stage when diagnosed and the main treatment option for these patients is platinumbased double-agent chemotherapy. However, traditional cytotoxic therapies have reached an efficacy plateau, with most of the patients who respond to them eventually progress [4]. Fortunately, breakthroughs in the molecular pathogenesis of NSCLC have facilitated the development of treatment targeting specific signaling pathways, and shed new light on NSCLC therapies.

Rearrangement of anaplastic lymphoma kinase (ALK) gene is also a potential target in NSCLC, the most common of which is EML4-ALK translocation [5]. The subsequent EML4-ALK fusion protein will be constitutively activated and transformed, activating the Ras and phosphoinositide 3-kinase (PI3K) signaling cascades [6], which might result in more aggressive tumor characteristics and possibly aggravated prognoses [7]. Crizotinib is a small-molecule tyrosine kinase inhibitor (TKI) of MET, ALK [8-10] and ROS1 [11, 12] kinases, which was approved for ALK-positive NSCLC by the US Food and Drug Administration in 2011 [13]. Several clinical studies have reported that Crizotinib led to improved outcomes $[14,15]$ and was extremely well tolerated [16].

However, the efficacy of Crizotinib in controlling systemic cancer has not effectively translated to the control of intracranial disease, with up to $60 \%$ of the patients developing brain metastases during the Crizotinib treatment [17], which may result from the poor central nervous system (CNS) penetration [18]. Hitherto, several case reports [18-30] and subset analyses of clinical trials [31] have evaluated the benefit of Crizotinib in controlling brain metastases, with various outcomes. These case reports 
cover patients of different characteristics, which make the outcomes unavailable to be compared. Herein, we conducted a retrospective analysis in advanced ALK-rearranged NSCLC patients, with the purpose of exploring how Crizotinib affects the control of brain metastases and the overall prognosis in the real world in an Asian population.

\section{RESULTS}

\section{Baseline characteristics of patients}

Baseline demographic and clinical characteristics of the enrolled patients are summarized in Table 1. A total of 34 patients were available for this retrospective study, of whom $30(88.2 \%)$ patients presented with stage IV disease at diagnosis, 20 (58.8\%) had baseline brain metastases at the initiation of Crizotinib treatment. Patients for this analysis were relatively young (median age, 51.5 years; range, 24-84 years), with $24(70.6 \%)$ patients younger than 60 years old, and most of them $(67.6 \%)$ were nonsmokers. All patients were determined ALK translocation ( 19 by FISH, 13 by Ventana IHC test, and the others by RT-PCR). Meanwhile, 21 of all the patients were EGFR mutation negative, and the other patients' EGFR mutation status was unavailable. At the time of brain metastases development, patient ECOG PS was 0 (35.3\% of patients), 1 (61.8\% of patients), and 2 (2.9\% of patients). After the brain metastases, 12 patients received local treatment (resection or radiotherapy) for brain metastases. A total of 27 patients $(79.4 \%)$ developed extra-cranial metastases (ECM), including 12 bone metastases, 9 intrapulmonary metastases, 8 extra pulmonary lymph node metastases, 7 pleural metastases, 4 liver metastases and 2 mediastinal lymph node metastases.

\section{Treatment, follow-up and disease control with Crizotinib}

Patients receiving Crizotinib at the first, second or $\geq$ third line of treatment were $9(26.5 \%), 16(47.1 \%)$ and $9(26.5 \%)$, respectively. Twenty-five patients were treated with chemotherapy at the first line, among which $15(60.0 \%)$ with Pemetrexed-based, 2 (8.0\%) with Gemcitabine-based and $8(32.0 \%)$ with Paclitaxel-based regimens. Median follow-up was 16.1 months.

The objective response rate (ORR) of all patients was $29.4 \%$ and the brain lesion ORR of patients with brain metastases before Crizotinib was $15.0 \%$. The median systemic progression-free survival (PFS) calculated from the diagnosis of advanced NSCLC was 17.7 months (95\% CI, 15.2 - 20.3) (Figure 1). There was a significant difference in systemic PFS between patients developing brain metastases before and after Crizotinib treatment (21.2 months vs. 13.9 months, $p=0.003$ ) (Figure 2). The median intracranial PFS (IC-PFS) among patients with brain metastases before Crizotinib was 20.7 months (95\% CI, 17.8 - 23.6). The median time to brain metastases from diagnosis of advanced NSCLC among patients with brain metastases after Crizotinib was 13.4 months (95\% CI, 5.9-20.9).

The median OS from diagnosis of advanced NSCLC was 32.5 months (Figure 3), with 10 patients died (29.4\%). 1- and 2-year overall survival rates were $97.1 \%$ and $71.1 \%$, respectively. There's no significant difference between the median OS of patients with or without extra-cranial metastases (32.5 months vs. not reached, $p=0.431)$. The median OS after brain metastases was not reached and the 1- and 2-year OS rates were $76.2 \%$ and $64.9 \%$, respectively.

For patients treated with Crizotinib after brain metastases, OS after brain metastases was significantly longer, compared with patients developing brain metastases during Crizotinib treatment (median OS, not reached vs. 10.3 months, respectively, $p=0.001$ ) (Figure 4). Either in patients receiving local treatment or not, there was a significant difference in OS after brain metastases between patients developing brain metastases before and after Crizotinib treatment $(p=0.042$ and 0.03 , respectively).

Among all the patients treated with chemotherapy at the first line, OS after brain metastases in patients with baseline brain metastases before Crizotinib was significantly superior to that in patients developing brain metastases after Crizotinib $(p=0.023)$. Whereas, among patients receiving Crizotinib at the first line, OS after brain metastases in patients with baseline brain metastases before Crizotinib didn't demonstrate such superior, compared with patients without baseline brain metastases $(p=0.089)$.

Among patients who developed brain metastases during Crizotinib administration, though the result was not significant by the cut-off date, time to brain metastases, calculated from the diagnosis of advanced NSCLC, was longer in patients receiving chemotherapy at the first line, compared with that in patients receiving Crizotinib at the first line (median time to brain metastases, 17.1 months vs. 10.5 months, $p=0.072$ ) (Figure 5).

\section{Adverse events and dose modification}

Crizotinib related adverse events (AE) that were found in $>5 \%$ of patients are summarized in Table 2 . The most common AEs of all grades (in $>30 \%$ of all the enrolled patients) include cardiac disturbances (CK-MB elevation, 62.9\%), hepatic disturbances (ALT increase, 42.9\%) and endocrine disruptions (hypocalcemia, 34.3\%). Dose reductions or temporary modifications were required in four patients due to the severe adverse reactions (one for prolonged QTc interval, one for hepatic disturbance, one for diarrhea and the other for hypocalcemia). 
Table 1: Patient demographic and clinical characteristics

\begin{tabular}{|c|c|c|c|c|c|c|}
\hline \multirow[b]{2}{*}{ Characteristics } & \multicolumn{2}{|c|}{$\begin{array}{c}\text { BM before the Treatment } \\
\text { of Crizotinib }\end{array}$} & \multicolumn{2}{|c|}{$\begin{array}{c}\text { No BM before the } \\
\text { Treatment of Crizotinib }\end{array}$} & \multicolumn{2}{|c|}{ All Enrolled Patients } \\
\hline & No. & $\%$ & No. & $\%$ & No. & $\%$ \\
\hline \multicolumn{7}{|l|}{ Age, years } \\
\hline Median & \multicolumn{2}{|c|}{55} & \multicolumn{2}{|c|}{51} & \multicolumn{2}{|c|}{51.5} \\
\hline Range & \multicolumn{2}{|c|}{$32-76$} & \multicolumn{2}{|c|}{$24-84$} & \multicolumn{2}{|c|}{$24-84$} \\
\hline \multicolumn{7}{|l|}{ Age distribution, years } \\
\hline$<60$ & 12 & 63.2 & 12 & 80.0 & 24 & 70.6 \\
\hline$\geq 60$ & 7 & 36.8 & 3 & 20.0 & 10 & 29.4 \\
\hline \multicolumn{7}{|l|}{ Sex } \\
\hline Male & 8 & 42.1 & 10 & 66.7 & 18 & 52.9 \\
\hline Female & 11 & 57.9 & 5 & 33.3 & 16 & 47.1 \\
\hline \multicolumn{7}{|l|}{ Smoking history } \\
\hline Yes & 5 & 26.3 & 6 & 40.0 & 11 & 32.4 \\
\hline No & 14 & 73.7 & 9 & 60.0 & 23 & 67.6 \\
\hline \multicolumn{7}{|l|}{ ECOG PS } \\
\hline 0 & 2 & 10.5 & 10 & 66.7 & 12 & 35.3 \\
\hline 1 & 17 & 89.5 & 4 & 26.7 & 21 & 61.8 \\
\hline 2 & 0 & 0 & 1 & 6.7 & 1 & 2.9 \\
\hline \multicolumn{7}{|c|}{ Extracranial metastases present } \\
\hline Yes & 7 & 36.8 & 15 & 100 & 22 & 64.7 \\
\hline No & 12 & 63.2 & 0 & 0 & 12 & 35.3 \\
\hline \multicolumn{7}{|l|}{ Operation history } \\
\hline Radical operation & 6 & 31.6 & 5 & 33.3 & 11 & 32.4 \\
\hline Palliative operation & 1 & 5.3 & 1 & 6.7 & 2 & 5.9 \\
\hline No & 12 & 63.2 & 9 & 60.0 & 21 & 61.8 \\
\hline
\end{tabular}

Abbreviations: BM, Brain Metastases; ECOG, Eastern Cooperative Oncology Group; PS, Performance Status.

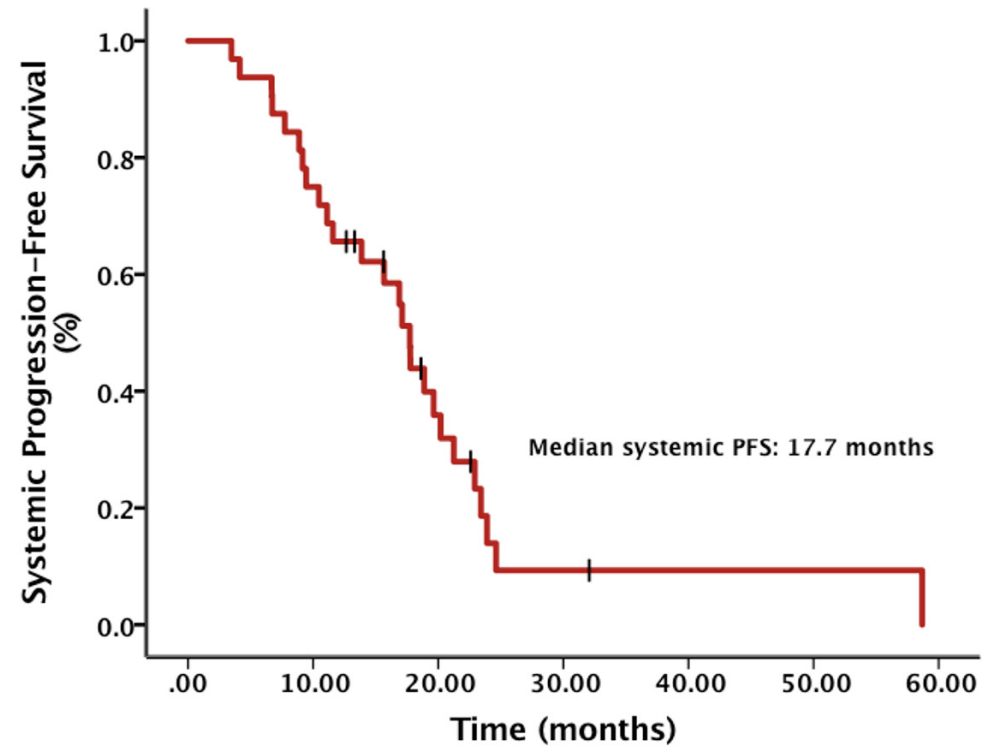

Figure 1: Systemic progression-free survival (PFS) from diagnosis of advanced NSCLC. 


\section{DISCUSSION}

Brain metastasis in NSCLC patients, which develops in $15 \%$ to $40 \%$ of ALK-rearranged patients after first diagnosis [32-34] and in approximately one third after the failure of at least one prior systemic therapy [31], is often considered as the terminal stage of advanced disease. Crizotinib is thought to be a small-molecule ALK inhibitor with poor penetration of blood-brain barrier.
A subset analysis of clinical trials PROFILE 1005 and 1007 has reported [31] that in ALK-rearranged advanced NSCLC patients treated with Crizotinib, the intracranial disease control rate (DCR) and ORR at 12 weeks were $56 \%(62 \%)$ and $18 \%(33 \%)$, with a median intracranial time to progression (TTP) of 7 months (13.2 months) in patients with previously untreated (treated) brain metastases, respectively. Lei YY et al. [35] has reported a similar ORR of Crizotinib between patients with and

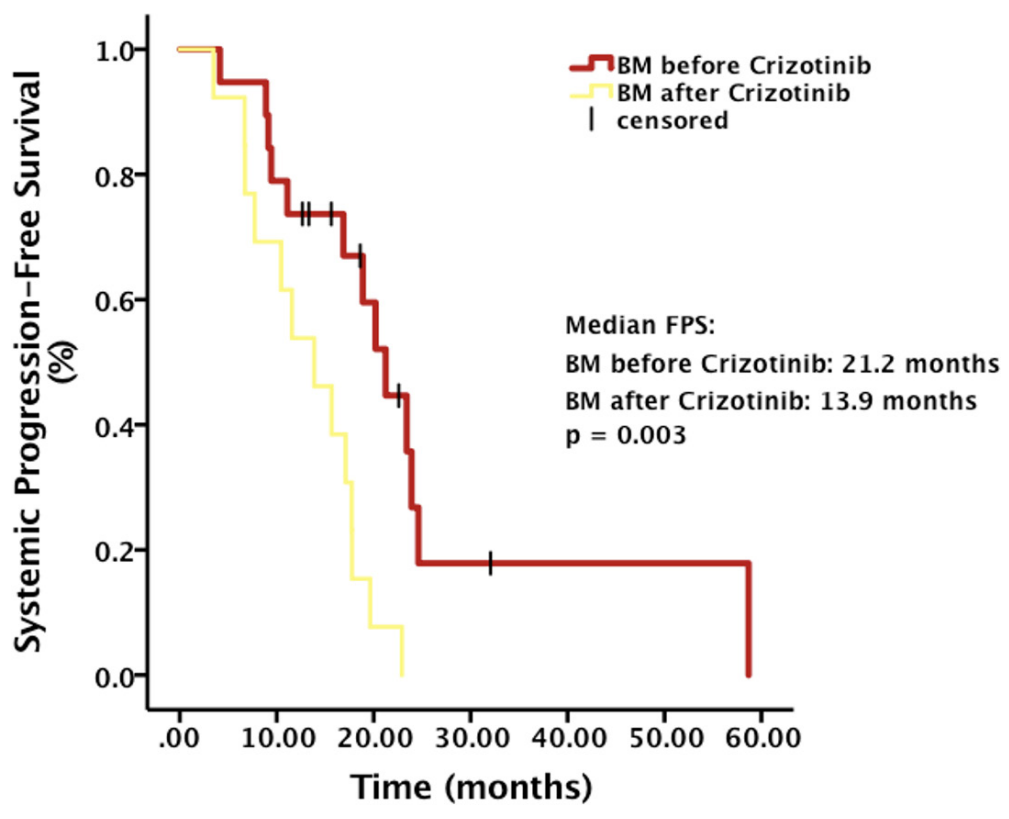

Figure 2: Systemic progression-free survival (PFS) from diagnosis of advanced NSCLC stratified by baseline brain metastases (BM) status.

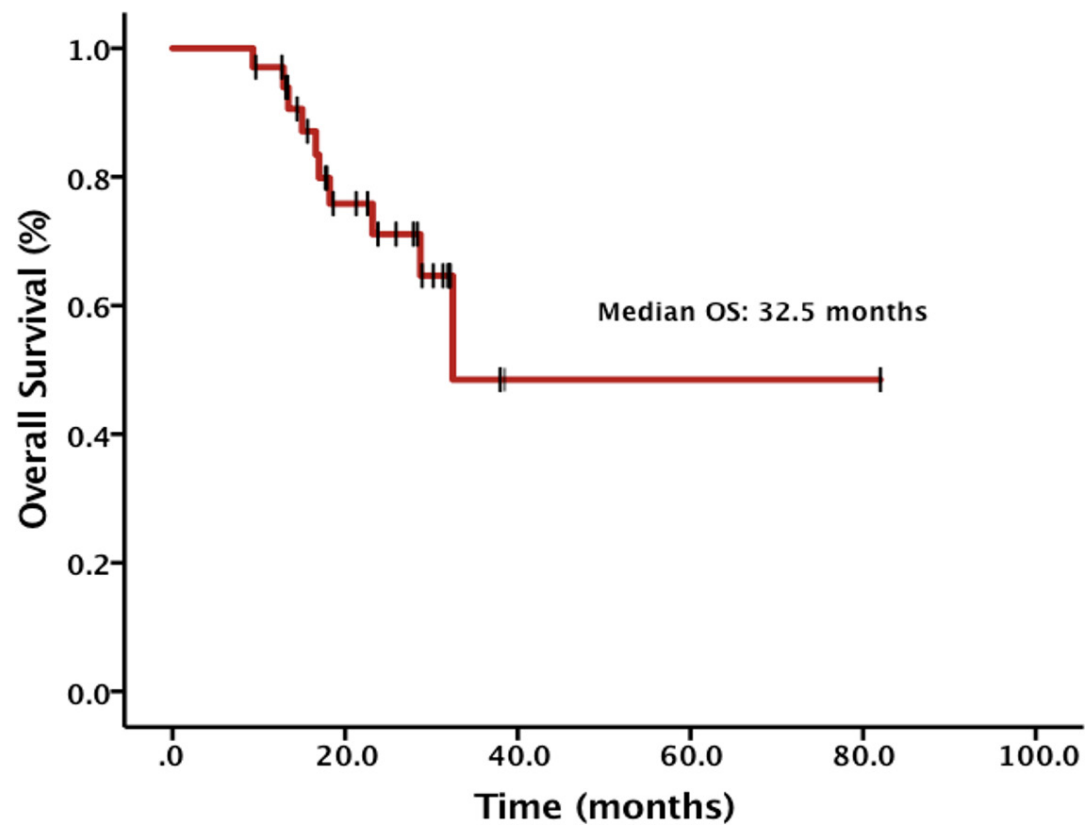

Figure 3: Overall survival (OS) from diagnosis of advanced NSCLC. 
without baseline brain metastases (68.4\% vs. $69.5 \%$, $p=0.904)$ and a significantly longer median PFS of patients without baseline brain metastases (10.0 months vs. 7.0 months, $p=0.021)$. However, a mature overall survival of these patients are still rudimentary.

To our knowledge, our retrospective study of Crizotinib in patients with advanced ALK-rearranged NSCLC and brain metastases represents the first and the largest data focusing on the overall prognosis of Chinese population in the real world.
In our study, the systemic ORR of all the patients was $29.4 \%$ and the brain lesion ORR of patients with brain metastases before Crizotinib was $15.0 \%$, which seemed to be obviously inferior to the results of clinical trials PROFILE 1005 and 1007. However, 1- and 2-year OS rates $(76.2 \%$ and $64.9 \%)$ in our study were similar to those observed by Johung KL et al. (72\% and 66\%) in a multi-institutional study which provided the largest data set of long-term outcomes for ALK-rearranged NSCLC patients with brain metastases in USA [36].

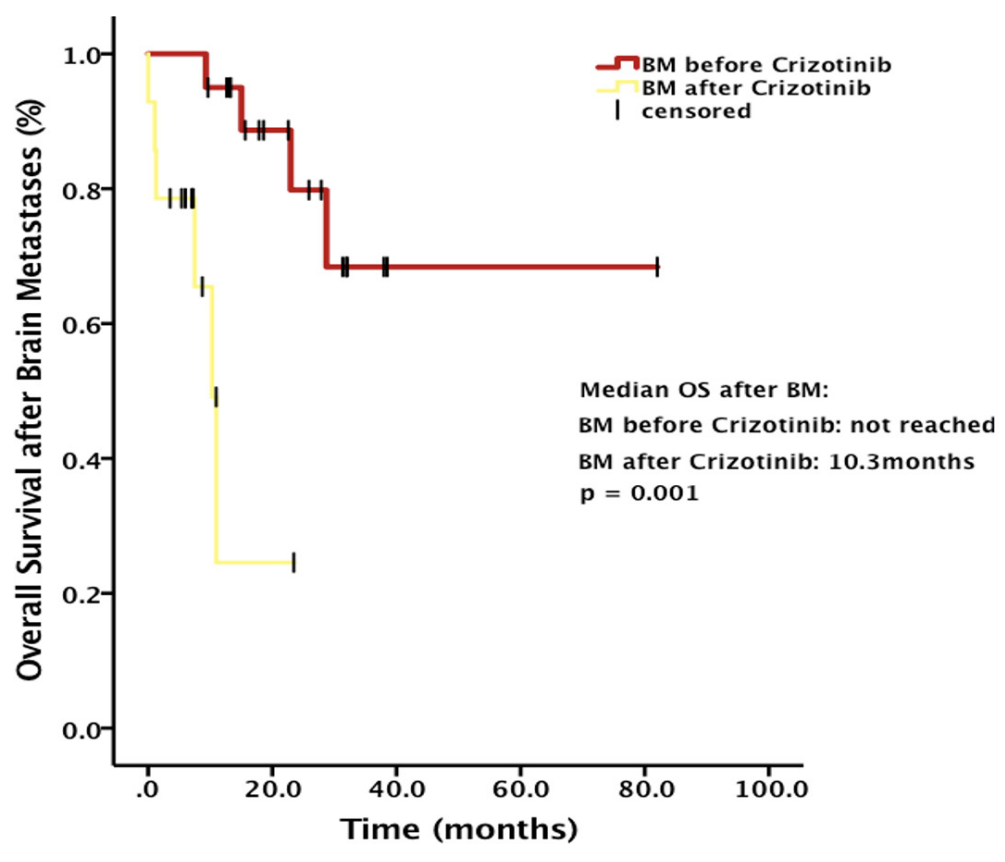

Figure 4: Overall survival (OS) after brain metastases (BM) stratified by baseline BM status.

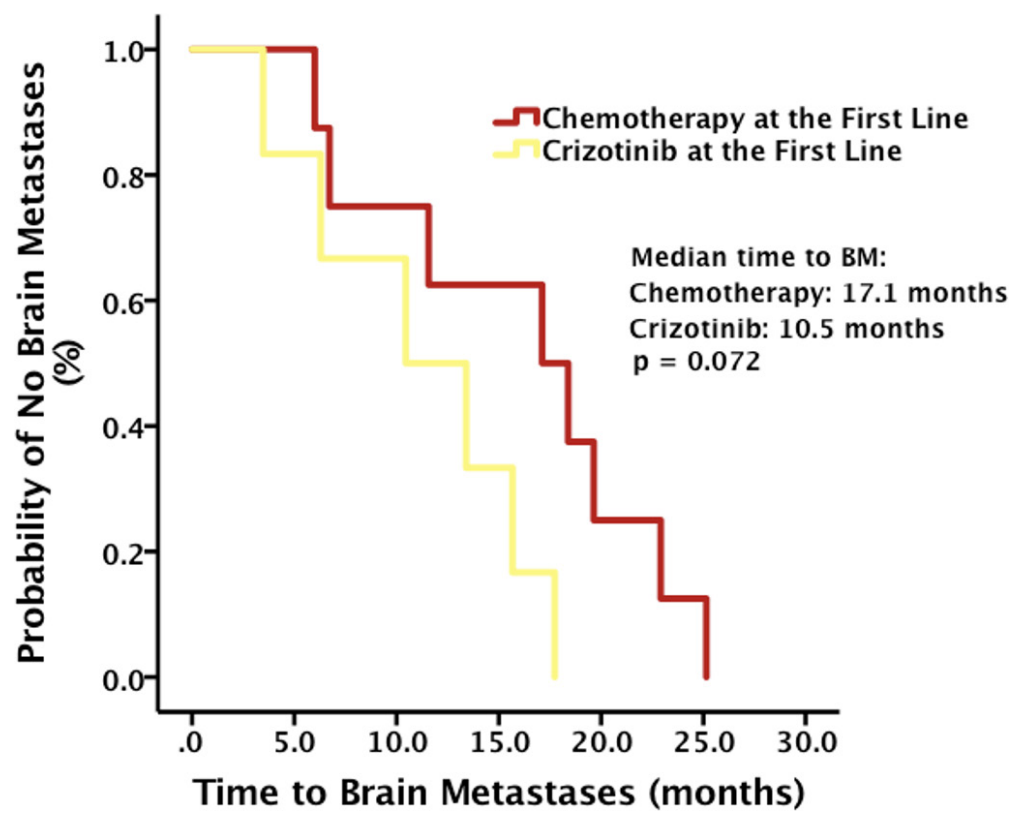

Figure 5: Time to brain metastases (BM) stratified by the first line treatment. 
Table 2: Crizotinib related adverse events

\begin{tabular}{|c|c|c|c|c|c|c|}
\hline \multirow[b]{2}{*}{ Adverse Events } & \multicolumn{2}{|c|}{$\begin{array}{c}\text { BM before the Treatment } \\
\text { of Crizotinib }\end{array}$} & \multicolumn{2}{|c|}{$\begin{array}{c}\text { No BM before the } \\
\text { Treatment of Crizotinib } \\
\end{array}$} & \multicolumn{2}{|c|}{ All Enrolled Patients } \\
\hline & All Grades & Grade $\geq 3$ & All Grades & Grade $\geq 3$ & All Grades & Grade $\geq 3$ \\
\hline \multicolumn{7}{|l|}{ Cardiac disturbances } \\
\hline CK-MB elevation & $13(68.4 \%)$ & 0 & $9(56.3 \%)$ & 0 & $22(62.9 \%)$ & 0 \\
\hline Peripheral edema & $6(31.6 \%)$ & 0 & 0 & 0 & $6(17.1 \%)$ & 0 \\
\hline QTc prolongation & $1(5.3 \%)$ & 0 & $2(12.5 \%)$ & 0 & $3(8.6 \%)$ & 0 \\
\hline \multicolumn{7}{|l|}{ Hepatic disturbances } \\
\hline ALT increase & $10(52.3 \%)$ & $1(5.3 \%)$ & $5(31.3 \%)$ & 0 & $15(42.9 \%)$ & $1(2.9 \%)$ \\
\hline \multicolumn{7}{|l|}{ Endocrine disruptions } \\
\hline Hypocalcemia & $6(31.6 \%)$ & 0 & $6(37.5 \%)$ & 0 & $12(34.3 \%)$ & 0 \\
\hline \multicolumn{7}{|l|}{ Bone marrow depression } \\
\hline Neutropenia & $5(26.3 \%)$ & 0 & $1(6.3 \%)$ & $1(6.3 \%)$ & $6(17.1 \%)$ & $1(2.9 \%)$ \\
\hline \multicolumn{7}{|c|}{ Gastrointestinal disturbances } \\
\hline Nausea/vomiting & $4(21.1 \%)$ & 0 & $1(6.3 \%)$ & 0 & $5(14.3 \%)$ & 0 \\
\hline Diarrhea & $3(15.8 \%)$ & 0 & $1(6.3 \%)$ & 0 & $4(11.4 \%)$ & 0 \\
\hline Constipation & $2(10.5 \%)$ & 0 & $2(12.5 \%)$ & 0 & $4(11.4 \%)$ & 0 \\
\hline \multicolumn{7}{|l|}{ Ocular disturbances } \\
\hline Diplopia & $2(10.5 \%)$ & 0 & $1(6.3 \%)$ & 0 & $3(8.6 \%)$ & 0 \\
\hline
\end{tabular}

Abbreviations: BM, Brain Metastases; CK-MB, Creatine Kinase-MB; ALT, Alanine Aminotransferase.

Our analyses suggested that among patients with baseline brain metastases before Crizotinib treatment, OS after brain metastases was significantly longer, compared with patients without brain metastases before Crizotinib treatment (median OS, not reached vs. 10.3 months, $p=0.001)$. There was also a significant difference in systemic PFS between patients developing brain metastases before and after Crizotinib treatment (21.2 months vs. 13.9 months, $p=0.003)$. In Johung KL et al. study, they contributed such difference to the control of CNS disease with radiotherapy. In our study, we also calculated the OS after brain metastases stratified by brain local treatment. Either in patients receiving local treatment or not, there was a significant difference in OS after brain metastases between patients developing brain metastases before and after Crizotinib treatment $(p=0.042$ and 0.03 , respectively). This result excluded the brain local treatment as a confounding factor of the OS in our study.

Furthermore, to investigate whether the first-line treatment had impact on the OS after brain metastases, we analyzed OS stratified by first-line treatment as well. Among all the patients treated with chemotherapy at the first line, OS after brain metastases in patients with brain metastases before Crizotinib was significantly superior to that in patients developing brain metastases after Crizotinib $(p=0.023)$. Such result indicated that these patients with brain metastases could still benefit from Crizotinib after first-line chemotherapy failure. Acquired resistance of Crizotinib may partly explain the result, and brain metastases during the Crizotinib treatment might be a strong signal of such resistance. Several studies have discussed about the mechanisms of such acquired resistance. The major mechanisms include ALK tyrosine kinase mutations, ALK copy number gain, activation of bypass signaling, and manipulation of downstream signaling pathways [37-41]. For patients with Crizotinib resistance, one promising therapeutic approach is secondgeneration ALK TKIs, such as Ceritinib, Alectinib and Brigatinib. Ceritinib, with more effective diffusion through blood-brain barrier, has demonstrated significant CNS activity in patients receiving prior Crizotinib, with a median intracranial duration of response time of 12.8 months [42].

Whereas, among patients receiving Crizotinib at the first line, OS after brain metastases in patients with baseline brain metastases before Crizotinib didn't demonstrate such superior, compared with patients without baseline brain metastases $(p=0.089)$. Moreover, even though the result was not significant by the cutoff date, time to brain metastases was longer in patients receiving chemotherapy at the first line, compared with patients receiving Crizotinib at the first line $(p=0.072)$. These results suggested that chemotherapy would be a better choice than Crizotinib for preventing intracranial progression. One probable reason for these findings might be associated with the poor penetration rate of Crizotinib 
into the cerebrospinal fluid (CSF). It was reported that the plasma concentration of Crizotinib was measured at $237 \mathrm{ng} / \mathrm{mL}$, while the CSF concentration was $0.616 \mathrm{ng} / \mathrm{mL}$, with a CSF-to-plasma ratio of 0.0026 [18].

There were several limitations for our current study. On the one hand, as a retrospective study involving patients from one cancer center, bias may have been introduced by the patient cohort. On the other hand, because of the relatively short follow-up time, we could see the trend that time to brain metastases was longer in patients receiving chemotherapy at the first line, compared with patients receiving Crizotinib, but the current result was not significant. Thus, a multicenter prospective study would be required to further confirm our results.

In conclusion, our data suggested that ALKrearranged NSCLC patients with baseline brain metastases may benefit more from Crizotinib than those developing brain metastases during Crizotinib treatment.

\section{MATERIALS AND METHODS}

\section{Patients}

We retrospectively investigated advanced NSCLC patients with brain metastases who underwent Crizotinib treatment at the Cancer Hospital of the Chinese Academy of Medical Sciences (Beijing, China) between April 2013 and October 2015. Patients meeting the following criteria were included: having a pathological diagnosis of NSCLC, developing brain metastases either before or during the treatment of Crizotinib, having treated with Crizotinib at any line of treatment. ALK translocation was determined by Ventana IHC test, FISH or RT-PCR. Brain metastases were diagnosed by $\mathrm{CT}$ or MRI. In this study, Crizotinib was administered at a dose of $250 \mathrm{mg}$ twice daily, with proper adjustments as needed. The follow-up was done by regular visits or telephone calls, and the information was collected into our database for analyses.

\section{Data extraction}

Baseline characteristics were recorded, including age, sex, stage at diagnosis, smoking history, ECOG PS scores, presence of extra-cranial metastases and operation history. Treatment dates, follow-up, treatment at the first line, presence of brain metastases at the initiation of Crizotinib treatment, dates of developing brain metastases, and dates of systemic or brain disease progression were also recorded. Adverse events were reported based on the National Cancer Institute Common Terminology Criteria for Adverse Events (CTCAE, version 3.0).

\section{Statistical analyses}

Statistical analyses were carried out by the SPSS 23.0 statistical software (SPSS, Inc., Chicago, IL,
USA). Systemic OS and PFS after diagnosis of NSCLC were analyzed with Kaplan-Meier method. KaplanMeier analysis was also used to calculate OS after brain metastases, PFS and time to brain metastases stratified by patients or treatment characteristics. The median event time and corresponding 95\% CI were also provided. The differences were assessed by the log-rank test. Statistical tests were two-sided, and $p<0.05$ was considered significant.

\section{CONFLICTS OF INTEREST}

The authors declare no conflicts of interest.

\section{REFERENCES}

1. Siegel RL, Miller KD, Jemal A. Cancer Statistics, 2015. CA Cancer J Clin. 2015; 65:5-29.

2. Chen W, Zheng R, Baade PD, Zhang S, Zeng H, Bray F, Jemal A, Yu XQ, He J. Cancer statistics in China, 2015. CA Cancer J Clin. 2016; 66:115-132.

3. Ettinger DS, Wood DE, Akerley W, Bazhenova LA, Borghaei H, Camidge DR, Cheney RT, Chirieac LR, D'Amico TA, Demmy TL, Dilling TJ, Govindan R, Grannis FW, et al. Non-small cell lung cancer, version 1.2015. J Natl Compr Canc Netw. 2014; 12:1738-1761.

4. Stinchcombe TE, Socinski MA. Current treatments for advanced stage non-small cell lung cancer. Proc Am Thorac Soc. 2009; 6:233-241.

5. Soda M, Choi YL, Enomoto M, Takada S, Yamashita Y, Ishikawa S, Fujiwara S, Watanabe $\mathrm{H}$, Kurashina $\mathrm{K}$, Hatanaka H, Bando M, Ohno S, Ishikawa $\mathrm{Y}$, et al. Identification of the transforming EML4-ALK fusion gene in non-small-cell lung cancer. Nature. 2007; 448:561-566.

6. Mosse YP, Wood A, Maris JM. Inhibition of ALK signaling for cancer therapy. Clin Cancer Res. 2009; 15:5609-5614.

7. Shaw AT, Yeap BY, Mino-Kenudson M, Digumarthy SR, Costa DB, Heist RS, Solomon B, Stubbs H, Admane S, McDermott U, Settleman J, Kobayashi S, Mark EJ, et al. Clinical features and outcome of patients with non-smallcell lung cancer who harbor EML4-ALK. J Clin Oncol. 2009; 27:4247-4253.

8. Christensen JG, Zou HY, Arango ME, Li Q, Lee JH, McDonnell SR, Yamazaki S, Alton GR, Mroczkowski B, Los G. Cytoreductive antitumor activity of PF-2341066, a novel inhibitor of anaplastic lymphoma kinase and c-Met, in experimental models of anaplastic large-cell lymphoma. Mol Cancer Ther. 2007; 6:3314-3322.

9. McDermott U, Iafrate AJ, Gray NS, Shioda T, Classon M, Maheswaran S, Zhou W, Choi HG, Smith SL, Dowell L, Ulkus LE, Kuhlmann G, Greninger P, et al. Genomic alterations of anaplastic lymphoma kinase may sensitize tumors to anaplastic lymphoma kinase inhibitors. Cancer Res. 2008; 68:3389-3395. 
10. Settleman J. Cell culture modeling of genotype-directed sensitivity to selective kinase inhibitors: targeting the anaplastic lymphoma kinase (ALK). Semin Oncol. 2009; 36:S36-41.

11. Yasuda H, de Figueiredo-Pontes LL, Kobayashi S, Costa DB. Preclinical rationale for use of the clinically available multitargeted tyrosine kinase inhibitor crizotinib in ROS1-translocated lung cancer. J Thorac Oncol. 2012; 7:1086-1090.

12. Bergethon K, Shaw AT, Ou SH, Katayama R, Lovly CM, McDonald NT, Massion PP, Siwak-Tapp C, Gonzalez A, Fang R, Mark EJ, Batten JM, Chen H, et al. ROS1 rearrangements define a unique molecular class of lung cancers. J Clin Oncol. 2012; 30:863-870.

13. Ou SH, Bartlett $\mathrm{CH}$, Mino-Kenudson M, Cui J, Iafrate AJ. Crizotinib for the treatment of ALK-rearranged nonsmall cell lung cancer: a success story to usher in the second decade of molecular targeted therapy in oncology. Oncologist. 2012; 17:1351-1375.

14. Shaw AT, Kim DW, Nakagawa K, Seto T, Crino L, Ahn MJ, De Pas T, Besse B, Solomon BJ, Blackhall F, Wu YL, Thomas M, O'Byrne KJ, et al. Crizotinib versus chemotherapy in advanced ALK-positive lung cancer. N Engl J Med. 2013; 368:2385-2394.

15. Leduc C, Besse B. Clinical benefit of continuing ALK inhibition with crizotinib beyond initial disease progression in patients with advanced ALK-positive NSCLC. Ann Oncol. 2014; 25:2092.

16. Kwak EL, Bang YJ, Camidge DR, Shaw AT, Solomon B, Maki RG, Ou SH, Dezube BJ, Janne PA, Costa DB, VarellaGarcia M, Kim WH, Lynch TJ, et al. Anaplastic lymphoma kinase inhibition in non-small-cell lung cancer. N Engl J Med. 2010; 363:1693-1703.

17. Zhang I, Zaorsky NG, Palmer JD, Mehra R, Lu B. Targeting brain metastases in ALK-rearranged non-small-cell lung cancer. Lancet Oncol. 2015; 16:e510-521.

18. Costa DB, Kobayashi S, Pandya SS, Yeo WL, Shen Z, Tan W, Wilner KD. CSF concentration of the anaplastic lymphoma kinase inhibitor crizotinib. J Clin Oncol. 2011; 29:e443-445.

19. Maillet D, Martel-Lafay I, Arpin D, Perol M. Ineffectiveness of crizotinib on brain metastases in two cases of lung adenocarcinoma with EML4-ALK rearrangement. J Thorac Oncol. 2013; 8:e30-31.

20. Ahn HK, Han B, Lee SJ, Lim T, Sun JM, Ahn JS, Ahn MJ, Park K. ALK inhibitor crizotinib combined with intrathecal methotrexate treatment for non-small cell lung cancer with leptomeningeal carcinomatosis. Lung Cancer. 2012; 76:253-254.

21. Chun SG, Choe KS, Iyengar P, Yordy JS, Timmerman RD. Isolated central nervous system progression on Crizotinib: an Achilles heel of non-small cell lung cancer with EML4ALK translocation? Cancer Biol Ther. 2012; 13:1376-1383.
22. Falk AT, Poudenx M, Otto J, Ghalloussi H, Barriere J. Adenocarcinoma of the lung with miliary brain and pulmonary metastases with echinoderm microtubuleassociated protein like 4-anaplastic lymphoma kinase translocation treated with crizotinib: a case report. Lung cancer. 2012; 78:282-284.

23. Pop O, Pirvu A, Toffart AC, Moro-Sibilot D. Disease flare after treatment discontinuation in a patient with EML4ALK lung cancer and acquired resistance to crizotinib. J Thorac Oncol. 2012; 7:e1-2.

24. Kaneda H, Okamoto I, Nakagawa K. Rapid response of brain metastasis to crizotinib in a patient with ALK rearrangement-positive non-small-cell lung cancer. J Thorac Oncol. 2013; 8:e32-33.

25. Kim YH, Ozasa H, Nagai H, Sakamori Y, Yoshida H, Yagi Y, Nakaoku T, Mishima M. High-dose crizotinib for brain metastases refractory to standard-dose crizotinib. J Thorac Oncol. 2013; 8:e85-86.

26. Kinoshita Y, Koga Y, Sakamoto A, Hidaka K. Long-lasting response to crizotinib in brain metastases due to EML4ALK-rearranged non-small-cell lung cancer. BMJ Case Rep. 2013; 2013.

27. Riess JW, Nagpal S, Neal JW, Wakelee HA. A patient with anaplastic lymphoma kinase-positive non-small cell lung cancer with development of leptomeningeal carcinomatosis while on targeted treatment with crizotinib. J Natl Compr Canc Netw. 2013; 11:389-394.

28. Takeda M, Okamoto I, Nakagawa K. Clinical impact of continued crizotinib administration after isolated central nervous system progression in patients with lung cancer positive for ALK rearrangement. J Thorac Oncol. 2013; 8:654-657.

29. Hayashi H, Okamoto I, Tanizaki J, Tanaka K, Okuda T, Kato A, Nishimura Y, Nakagawa K. Cystic brain metastasis in non-small-cell lung cancer with ALK rearrangement. J Clin Oncol. 2014; 32:e122-124.

30. Chun SG, Iyengar P, Gerber DE, Hogan RN, Timmerman RD. Optic neuropathy and blindness associated with crizotinib for non-small-cell lung cancer with EML4ALK translocation. J Clin Oncol. 2015; 33:e25-26.

31. Costa DB, Shaw AT, Ou SH, Solomon BJ, Riely GJ, Ahn MJ, Zhou C, Shreeve SM, Selaru P, Polli A, Schnell P, Wilner KD, Wiltshire R, et al. Clinical Experience With Crizotinib in Patients With Advanced ALK-Rearranged Non-Small-Cell Lung Cancer and Brain Metastases. J Clin Oncol. 2015; 33:1881-1888.

32. Kang HJ, Lim HJ, Park JS, Cho YJ, Yoon HI, Chung JH, Lee JH, Lee CT. Comparison of clinical characteristics between patients with ALK-positive and EGFR-positive lung adenocarcinoma. Respir Med. 2014; 108:388-394.

33. Fallet V, Cadranel J, Doubre H, Toper C, Monnet I, Chinet T, Oliviero G, Foulon G, De Cremoux H, Vieira T, Antoine M, Wislez M. Prospective screening for ALK: 
clinical features and outcome according to ALK status. Eur J Cancer. 2014; 50:1239-1246.

34. Doebele RC, Lu X, Sumey C, Maxson DA, Weickhardt AJ, Oton AB, Bunn PA, Jr., Baron AE, Franklin WA, Aisner DL, Varella-Garcia M, Camidge DR. Oncogene status predicts patterns of metastatic spread in treatment-naive nonsmall cell lung cancer. Cancer. 2012; 118:4502-4511.

35. Lei YY, Yang JJ, Zhong WZ, Chen HJ, Yan HH, Han JF, Yang LL, Wu YL. Clinical efficacy of crizotinib in Chinese patients with ALK-positive non-small-cell lung cancer with brain metastases. J Thorac Dis. 2015; 7: 1181-1188.

36. Johung KL, Yeh N, Desai NB, Williams TM, Lautenschlaeger T, Arvold ND, Ning MS, Attia A, Lovly CM, Goldberg S, Beal K, Yu JB, Kavanagh BD, et al. Extended Survival and Prognostic Factors for Patients With ALK-Rearranged Non-Small-Cell Lung Cancer and Brain Metastasis. J Clin Oncol. 2016; 34:123-129.

37. Katayama R, Khan TM, Benes C, Lifshits E, Ebi H, Rivera VM, Shakespeare WC, Iafrate AJ, Engelman JA, Shaw AT. Therapeutic strategies to overcome crizotinib resistance in non-small cell lung cancers harboring the fusion oncogene EML4-ALK. Proc Natl Acad Sci USA. 2011; 108:7535-7540.

38. Sasaki T, Koivunen J, Ogino A, Yanagita M, Nikiforow S, Zheng W, Lathan C, Marcoux JP, Du J, Okuda K,
Capelletti M, Shimamura T, Ercan D, et al. A novel ALK secondary mutation and EGFR signaling cause resistance to ALK kinase inhibitors. Cancer Res. 2011; 71:6051-6060.

39. Katayama R, Shaw AT, Khan TM, Mino-Kenudson M, Solomon BJ, Halmos B, Jessop NA, Wain JC, Yeo AT, Benes C, Drew L, Saeh JC, Crosby K, et al. Mechanisms of acquired crizotinib resistance in ALK-rearranged lung Cancers. Sci Transl Med. 2012; 4:120ra117.

40. Camidge DR, Pao W, Sequist LV. Acquired resistance to TKIs in solid tumours: learning from lung cancer. Nat Rev Clin Oncol. 2014; 11:473-481.

41. Lovly CM, McDonald NT, Chen H, Ortiz-Cuaran S, Heukamp LC, Yan Y, Florin A, Ozretic L, Lim D, Wang L, Chen Z, Chen X, Lu P, et al. Rationale for co-targeting IGF-1R, ALK in ALK fusion-positive lung cancer. Nat Med. 2014; 20:1027-1034.

42. Felip E, Crino L, Kim DW, Spigel DR, Nishio M, Mok T, Scagliotti G, Cesic D, Sutradhar S, Shaw AT. 141PD: Whole body and intracranial efficacy of ceritinib in patients (pts) with crizotinib (CRZ) pretreated, ALK-rearranged (ALK+) non-small cell lung cancer (NSCLC) and baseline brain metastases (BM): Results from ASCEND-1 and ASCEND-2 trials. J Thorac Oncoly. 2016; 11:S118-119. 